Revista Destaques Acadêmicos, Lajeado, v. 9, n. 1, 2017. ISSN 2176-3070

DOI: http://dx.doi.org/10.22410/issn.2176-3070.v9i1a2017.1325

www.univates.br/revistas

\title{
QUALIDADE EM SERVIÇOS: ANALISANDO O ATENDIMENTO NA PRESTAÇÃO DE SERVIÇOS DE MEDICINA OCUPACIONAL
}

\author{
Jóice Andréia Fiegenbaum Lenhart ${ }^{1}$, Gerson José Bonfadini ${ }^{2}$
}

\begin{abstract}
Resumo: Atualmente, as empresas buscam adaptar-se para manterem-se competitivas, fazendo uso de ferramentas de gestão e planejamento. Destarte, aliado ao crescimento do setor de prestação de serviço, cresce a necessidade de qualidade dos serviços na Medicina Ocupacional, onde se deve atender exigências legais e satisfazer a empresa e o funcionário. Assim, analisou-se a percepção da qualidade do serviço prestado pelos médicos de Medicina Ocupacional às empresas de Teutônia/RS. Para tanto, abordouse diversos conceitos para alcançar os objetivos propostos, permitindo analisar e descrever a situação atual, bem como, fazer uma análise crítica, apontando melhorias a uma prestação do serviço satisfatória. O método e a análise foram qualitativos, onde os procedimentos técnicos foram bibliográficos, análise documental e levantamento de dados com entrevistas in loco. Os resultados do estudo podem contribuir à qualificação dos serviços, melhorando o atendimento das necessidades e expectativas de empresas clientes e funcionários e maior desempenho em relação à concorrência.
\end{abstract}

Palavras-chave: Qualidade de serviços. Atendimento. Medicina Ocupacional. Teutônia / RS.

\section{INTRODUÇÃO}

As mudanças na economia, gerando um mundo mais globalizado e o avanço da tecnologia obrigam as empresas a se adaptarem para se manterem competitivas no mercado. Essas necessidades são sentidas em todos os segmentos, e vêm se acentuando pelos mercados que se tornam mais complexos e diversificados. Sendo assim, as empresas que aplicam técnicas de gestão eficazes e fazem o planejamento de suas ações futuras têm mais facilidade de adaptação e estão à frente de seus concorrentes. Dentro desta perspectiva,

1 Acadêmica do curso de Administração com Linha de Formação Específica em Gestão em Turismo da UNIVATES, Lajeado/RS. jafiegenbaum@yahoo.com.br

2 Doutor em Comunicação Social pela Pontifícia Universidade Católica do Rio Grande do Sul; professor do curso de Administração da UNIVATES, Lajeado/RS. bonfadini@univates.br 
conforme Corrêa e Caon (2009), o mercado da prestação de serviços tem crescido significativamente nos últimos anos, provocando um aumento na qualidade dos mesmos. Estes são capazes de maximizar os lucros e fidelizar os clientes, quando realizados de forma eficiente. No Rio Grande do Sul, é importante lembrar que o setor de serviços representa $69 \%$ da mão de obra empregada (FECOMERCIO-RS, texto digital).

Atualmente, com a maior rigidez em relação à obrigatoriedade da Medicina Ocupacional, cresce a procura por profissionais que atuem nesta área (MINISTERIO DO TRABALHO E EMPREGO, texto digital). Para tanto, empresas e médicos do trabalho devem trabalhar em sintonia, assegurando a qualidade de vida dos colaboradores a partir de uma avaliação clínica especializada da saúde do trabalhador. Como qualquer outra empresa prestadora de serviços, os consultórios médicos buscam aumentar seu volume de clientes e a satisfação dos mesmos. Logo, é preciso compreender a percepção dos clientes em relação à qualidade na prestação de serviço.

Visando à prestação de serviços adequada entre as partes envolvidas, agregar valor ao serviço prestado, evidenciando a preocupação em prestar um serviço de qualidade e que pode ser percebido pelo cliente, o presente estudo buscou responder o seguinte problema de pesquisa: Qual é a percepção da qualidade do serviço prestado pelos médicos de Medicina Ocupacional às empresas da cidade de Teutônia/RS? Para tanto, objetivou-se analisar a percepção da qualidade do serviço prestado pelos médicos de Medicina Ocupacional às empresas da cidade de Teutônia/RS; e de forma mais específica descrever o perfil das empresas; entender por meio das dimensões de qualidade em serviços, o que os clientes organizacionais esperam no atendimento; avaliar a percepção dos clientes quanto à qualidade dos serviços prestados; e propor sugestões de melhorias a partir dos resultados obtidos.

Assim, o presente justifica-se pela atual realidade, onde as empresas buscam qualidade na prestação de serviços, como um diferencial frente à concorrência. Para a acadêmica, permite aplicar na prática os conhecimentos adquiridos no decorrer do curso. Além disso, conhecer melhor o ambiente organizacional, a fim de agregar e desenvolver conhecimentos para desempenhar suas atividades profissionais com maior sucesso e competência.

Aos consultórios médicos, o presente pode ser visto como um momento de aproveitar o conhecimento acadêmico para que sejam analisadas atividades, apontando oportunidades de melhoria visando a um número de clientes cada vez maior e com uma prestação de serviços de qualidade. Assim, as empresas tiveram a oportunidade de expressar satisfações e insatisfações com o intuito de os mesmos darem continuidade nos pontos positivos e desenvolver, dentro de sua realidade, um plano de ação para solucionar as insatisfações citadas pelos entrevistados, as quais podem ser também de demais clientes. 


\section{REFERENCIAL TEÓRICO}

\subsection{A importância dos serviços na economia}

A administração das operações de serviço, de acordo com Johnston e Clark (2009), pode ser definida como uma atividade que diz respeito a que serviço é prestado e como ele é fornecido aos clientes. Deste modo, envolve entender as necessidades dos clientes, gerenciar os processos de prestação dos serviços, assegurar que os objetivos estabelecidos sejam atendidos e, ao mesmo tempo, prestar atenção à melhoria contínua dos serviços.

O setor de serviços, conforme Fitzsimmons e Fitzsimmons (2014), teve um crescimento significativo nos últimos 50 anos. Lovelock, Wirtz e Hemzo (2011) complementam que a participação do setor de serviços está crescendo até mesmo em países com economia emergente, os serviços vêm crescendo e contribuindo significativamente para o Produto Interno Bruto (PIB). No Brasil, além de o setor de serviços ser responsável pela maior parte da economia, também emprega mais da metade dos trabalhadores formais.

\subsection{Conceito de serviço}

Conceituar serviço é algo complexo, pois é vasto o campo de atuação, permeando diversas áreas. Assim, para Johnston e Clark (2009), serviço é a combinação dos resultados e experiências que são propiciadas ao cliente e recebidos por ele. Destarte, os clientes julgam a qualidade do mesmo por meio da experiência e do resultado. O conceito de serviço, segundo os autores, é a proposição do negócio, é o modo pelo qual o cliente percebe os serviços. Assim, pode ser visto como uma figura mental a ser assumida por clientes, funcionários e acionistas sobre o serviço fornecido pela organização. Moreira (1998) ressalta que a atividade de serviços obriga a um contato mais estreito com o cliente. Portanto, a prestação de serviço, facilmente, se confunde com o seu consumo. Deste modo, para o autor, a prestação do serviço médico dá-se no momento de seu consumo, quando o médico dá a informação ao paciente.

\subsubsection{Características do serviço}

Téboul (1999) ressalta a importância das características do serviço, a fim de facilitar a compreensão do mesmo em relação a produto, logo, devem ser analisadas as seguintes:

- A imaterialidade do serviço: os serviços são intangíveis, logo, um serviço não pode ser apresentado ou comprado assim como um bem;

- Serviço é perecível e não pode ser estocado: como se trata de uma prestação, não é possível apropriar-se dele e nem estocá-lo. Assim, o consumo ocorre no momento de sua produção. Portanto, os serviços não consumidos 
estão perdidos, ou seja, se a demanda for maior que a oferta, o cliente estará "estocado" numa fila de espera, ou será perdido;

- A qualidade da prestação: o serviço é uma prestação única na presença do cliente e é preciso ter êxito da primeira vez. Ressalta-se que a prestação de serviço não pode ser melhorada ou corrigida sem que o cliente esteja consciente disso. Assim, em caso de algum reparo, o cliente deve ser "recuperado", pois sua percepção é imediata, subjetiva e qualitativa;

- A diversidade e a volatilidade dos clientes: A presença do cliente no processo de prestação cria uma fonte de incerteza, já que durante a prestação os funcionários entram em contato com os clientes, cujo comportamento é imprevisível. Um mesmo serviço pode deparar-se com uma variedade de solicitações e mudanças de opinião durante a prestação;

- A implicação do consumidor: os clientes fazem parte integrante da prestação e, portanto, têm um papel maior a desempenhar, tendo em vista que os mesmos conduzem e controlam o prestador, desempenhando um papel importante para melhorar a eficácia;

- Localização e Redes: Téboul (1999) afirma que, tendo em vista que os serviços são produzidos e consumidos ao mesmo tempo, é essencial dispor de uma localização adequada para estar próximo aos consumidores. Assim, a facilidade de acesso e a localização privilegiada desempenham um papel importante.

\subsection{Conceito de Qualidade}

A qualidade deve ser vista como uma propriedade, atributo ou condição das coisas ou das pessoas, capaz de distingui-las das outras e de lhes determinar a natureza, afirma Ferreira (apud HENRIQUE et al., 2013). Neste sentido, no entender de Ribeiro (2007), fazer a qualidade acontecer no atendimento é um processo complexo que necessita de uma ação contínua, na qual é preciso o empenho e a participação de todos os membros da organização.

Henrique et al. (2013) ressalta que quando os princípios da qualidade são adotados e acompanhados de uma ação correspondente, significa que a administração pretende manter a empresa em atividade e, pode representar o diferencial de valores, ao observar aspectos positivos e negativos nas relações interpessoais. Assim, a busca pela qualidade visa vencer a concorrência, sedimentar a imagem da empresa no mercado, aumentar o grau de confiança dos consumidores e promover a autorrealização dos que produzem.

\subsection{Qualidade em serviço}

De acordo com Ribeiro (2007), por qualidade, entende-se a busca constante da excelência em tudo o que uma empresa faz, sem se limitar à área de produção. Ela tem por base a geração de produtos ou serviços que atendam 
inteiramente aos pedidos dos clientes. O autor salienta que é preciso fazer certo da primeira vez, sendo que qualidade não é um programa, mas um processo que possui uma cadeia de clientes/fornecedores internos e externos, onde os requisitos são o elo desta cadeia, onde o aperfeiçoamento deve ser contínuo.

Eleutério e Souza (2002) advertem que os consumidores escolhem seus prestadores de serviços por meio da comparação das percepções que têm do serviço que recebem com o esperado. Assim, as autoras argumentam que, qualidade é aquilo que é percebido pelos clientes. Deste modo, percebe-se que a frustração das expectativas é muito frequente e decorre, geralmente, da diferença entre o real e o esperado.

\subsubsection{Dimensões de Qualidade em Serviço}

Fitzsimmons e Fitzsimmons (2014) lembram que a qualidade em serviço é um assunto complexo, o que pode ser percebido na necessidade de uma definição com cinco dimensões. Assim, Zeithaml, Parasuraman e Berry (apud GIANESI e CORRÊA, 2009) já afirmavam o mesmo e salientavam que é preciso identificar os critérios que são avaliados pelos clientes em relação ao serviço de que necessitam. Os autores criaram uma lista com cinco critérios para avaliar a percepção dos clientes quanto à qualidade do serviço, isto é, o processo por meio do qual um cliente seleciona, organiza e interpreta as informações recebidas para criar uma imagem do que está recebendo: confiabilidade, presteza (sensibilidade), conhecimento (segurança), empatia e bens tangíveis.

Bens tangíveis - a aparência das instalações físicas, dos equipamentos, dos funcionários e do material de comunicação. Grönroos (2009) enfatiza que este quesito deve estar relacionado com a atratividade das instalações, equipamentos e materiais utilizados, bem como a aparência dos funcionários;

Confiabilidade - o serviço é realizado exatamente como foi prometido e é confiável. Garvin (1992) salienta que a confiabilidade reflete a probabilidade de ocorrer algum erro ou falha. Segundo o autor, a má conformidade e confiabilidade acabam levando a enormes custos decorrentes destas falhas;

Conhecimento (Segurança) - o conhecimento e a simpatia dos funcionários e sua habilidade de transmitir confiança e segurança. Segundo Grönroos (2009), é importante para o cliente saber que a organização tem habilidade e conhecimento necessário para solucionar o problema de acordo com os padrões. Fitzsimmons e Fitzsimmons (2014) complementam que esta dimensão inclui competência para realizar o serviço, comunicação efetiva e a ideia de que a organização está realmente interessada em prestar o melhor para o cliente;

Empatia - os clientes recebem atenção individualizada no atendimento. Grönroos (2009) salienta que é importante que o cliente perceba que a organização está dedicada em resolver seus problemas. Albrecht e Bradford (1992) descrevem que o cliente jamais deve ser tratado com apatia, pois o 
mesmo deseja ser tratado com individualidade e sentir-se importante para a organização;

Presteza - os clientes são adequadamente ajudados por quem os atende e o serviço acontece dentro do prazo estipulado. Grönroos (2009) destaca a importância dos profissionais e sua equipe de trabalho transmitir disposição e presteza tomando a iniciativa de cuidar dos problemas dos clientes, mostrando que podem pensar por conta própria sem seguir somente as regras previamente estipuladas.

\subsubsection{Percepção do cliente}

Os clientes percebem serviços de maneira diferenciada, tendo em vista que a qualidade do serviço é variável de acordo com cada pessoa (LAS CASAS, 1999). O autor ressalta ainda, que é preciso considerar os diversos estímulos físicos que contribuem para a percepção, além dos fatores como necessidades e estado de ânimo. Neste sentido, Johnston e Clark (2009), salientam que a qualidade do serviço, quando está baseada na perspectiva de operações, depende de um atendimento consistente da especificação.

Diamante (2003) cita Lovelock e Wright (2001) para afirmar que a percepção é um fator intangível, é a maneira como o cliente interpreta as informações que recebe. $\mathrm{O}$ aprendizado é aquilo que o cliente já teve como experiência anterior e as convicções e atitudes são noções que o mesmo tem sobre o serviço adquirido. Portanto, a expectativa pode ser definida como a esperança em supostos direitos, probabilidades ou promessas, tendo em vista, que as necessidades são desejos subconscientes que dizem respeito a questões existenciais e de identidade. Ao analisar o serviço enquanto faz uso do mesmo, o cliente levará em consideração suas expectativas, que, muitas vezes podem ser diferentes de suas necessidades.

\subsubsection{Atendimento}

De acordo com Paladini (apud PEREIRA; BERTOLINI; BRANDALISE, 2003?), o atendimento ao público, segundo a gestão da qualidade deve ser direcionada para ações que buscam maior contato com o cliente, definição de seus interesses, preferências, exigências, necessidades, conveniências, etc. O atendimento, segundo Prazeres (apud BAPTISTA; LEONARDT, 2011) é como a velocidade, a competência e a disponibilidade com que os usuários são acolhidos e lhes são prestados os serviços solicitados. Assim, é importante que a busca pela qualidade nos serviços, aliado a um atendimento com qualidade sejam constantes.

Segundo Dalledone (apud GONÇALVES et al., 2010), o bom atendimento ao cliente deve ser a combinação entre qualidade, eficiência, custo do produto, distribuição e rapidez. O autor salienta que todos esses elementos 
são promotores do ambiente que facilita a implantação ou a conquista da fidelidade, bem como, a percepção de qualidade do serviço.

\subsection{Qualidade do serviço em saúde}

Borba, Mendes e Silveira (2004) relatam que a qualidade em saúde se dá em saber ouvir e dialogar com o cliente. $\mathrm{Na}$ área da saúde, qualidade se dá por satisfação do cliente e por confiança nos serviços. O que satisfaz o cliente é a percepção de qualidade; mas, acima da percepção do cliente, está a questão técnica, capaz de ser mensurada por controles técnicos e pelo cumprimento de padrões de exigências técnico-científicas.

Gonçalves et al. (2010) afirmam que uma boa definição para a qualidade do atendimento médico parece simples, porém, é um problema constante para os administradores da assistência médica e para as pessoas que desejam estudar o setor. Isso ocorre por ser definida de várias formas e por cada definição atender a um tipo especial de problema.

\subsection{Medicina Ocupacional}

As mudanças que vem ocorrendo no trabalho provocaram alterações perceptíveis na composição do processo de adoecimento e morte no trabalho (VIEIRA, 1995). Assim, conforme o autor, as péssimas condições de trabalho e de vida fazem com que cresça a preocupação quanto a acidentes e doenças do trabalho.

Bellusci (2010) lembra que a saúde e a doença do trabalhador são indicadas pelo processo de trabalho que envolve relações econômicas, sociais e tecnológicas. Segundo ela, estas determinam a exposição a fatores de risco, sejam eles, físicos, químicos, biológicos, mecânicos e aqueles provindos da organização laboral. Assim, salienta a importância de ações de saúde do trabalhador estarem integradas com as de saúde ambiental, tendo em vista que os riscos nos processos produtivos podem também afetar o meio ambiente e a população em geral. A profissionalização da medicina é uma realidade que, às vezes, pode não parecer agradável, mas que, segundo Selles e Minadeo (2006), é imprescindível.

\subsection{Norma Regulamentadora $\mathrm{n}^{\circ} 7$}

A Norma Regulamentadora $\mathrm{n}^{\circ} 7$, de acordo com MINISTÉRIO DO TRABALHO E EMPREGO (texto digital), integra a Portaria $n^{\circ} 3.214 / 78$, emitida pelo Ministério do Trabalho, que visa regulamentar a Lei $\mathrm{n}^{\circ} 6.514 / 77$ que foi responsável pela alteração do Capítulo V do Título II da Consolidação das Leis do Trabalho (CLT). Assim, esta Norma estabelece:

A obrigatoriedade de elaboração e implementação, por parte de todos os empregadores e instituições que admitam trabalhadores 
como empregados, do Programa de Controle Médico de Saúde Ocupacional - PCMSO, com o objetivo de promoção e preservação da saúde do conjunto dos seus trabalhadores. [...] O PCMSO é parte integrante do conjunto mais amplo de iniciativas da empresa no campo da saúde dos trabalhadores, devendo estar articulado com o disposto nas demais NR. [...] O PCMSO deverá considerar as questões incidentes sobre o indivíduo e a coletividade de trabalhadores, privilegiando o instrumental clínico-epidemiológico na abordagem da relação entre sua saúde e o trabalho. (MINISTÉRIO DO TRABALHO E EMPREGO, texto digital).

O PCMSO deve ter caráter de prevenção, rastreamento e diagnóstico precoce dos agravos à saúde que tenham alguma relação com o trabalho. Portanto, deve ser planejado e implantado com base nos riscos à saúde dos trabalhadores, especialmente aqueles identificados nas avaliações previstas nas demais NR. Ele deve incluir, entre outros, a realização obrigatória dos exames médicos: admissional; periódico; de retorno ao trabalho; de mudança de função; e demissional. Tais exames devem compreender uma avaliação clínica, abrangendo anamnese ocupacional e exame físico e mental, bem como, exames complementares, realizados de acordo com os termos específicos das NR e seus anexos.

\section{8 Ética médica nos serviços de saúde ocupacional}

Para Fortes (1998), a ética se refere à reflexão crítica em relação ao comportamento humano, esta reflexão interpreta, discute, problematiza e investiga os valores e comportamento moral. Ela não é contrária ao desenvolvimento técnico-científico, mas, segundo Arges Junior (2000), considera que os limites a serem estabelecidos devem ser dados pela garantia do respeito à dignidade humana. Assim, todo paciente, deve ser tratado em benefício de suas necessidades de saúde e não para satisfazer interesses de terceiros, da ciência, dos profissionais de saúde ou de interesses industriais e comerciais. No mesmo sentido, Vieira (1995) e Marano (2001) preconizam a importância da ética médica, portanto, afirma que é importante o médico do trabalho manter-se na neutralidade, no meio-termo.

\section{MÉTODO DE PESQUISA}

O tipo de pesquisa foi definido de acordo com os objetivos deste estudo, que buscou a percepção de qualidade do serviço prestado pelos médicos de medicina ocupacional às empresas de Teutônia, RS. Assim, quanto à sua natureza foi uma pesquisa aplicada, onde sua natureza de abordagem foi qualitativa e exploratória, quanto aos seus objetivos.

No decorrer da pesquisa foram utilizados procedimentos técnicos para a elaboração da mesma, tais como: pesquisa bibliográfica, documental 
e de campo, a fim de buscar informações técnico-científicas sobre os temas abordados para transmitir maior credibilidade ao assunto; analisar os relatórios e arquivos disponibilizados pela Prefeitura Municipal de Teutônia quanto ao número de empresas estabelecidas na cidade, solicitados por meio de protocolo junto à Secretaria da Fazenda, e junto à Secretaria de Saúde, quanto ao número de médicos de Medicina Ocupacional que atuam na cidade.

A unidade de análise foi constituída por empresas sediadas em Teutônia, RS. As empresas classificam-se de acordo com o setor em que atuam, sendo que, por grau de significância na economia, são classificadas como: industrial, comercial e prestação de serviço. Diante do tamanho da cidade e o perfil das empresas serem do tipo empresa familiar, do tipo micro, pequeno e médio porte, decidiu-se, para este estudo, reclassificá-las em três grupos: empresas que empregam até 10 trabalhadores, empresas que empregam de 11 a 40 trabalhadores e empresas que tenham mais de 40 trabalhadores. Foram entrevistadas 30 empresas, sendo 10 empresas de cada grupo entre os dias 07 e 20 de abril de 2016. Adotou-se a técnica de Anotação para melhor aplicação e registro dos dados.

Para atingir o objetivo geral do trabalho foram abordadas, questões voltadas ao perfil, percepção de qualidade envolvendo as seguintes dimensões: bens tangíveis, confiabilidade, conhecimento, empatia e presteza. A entrevista foi elaborada a partir de um quadro teórico, onde foram aplicados os conceitos do referencial teórico, o autor que elaborou a teoria, os objetivos específicos e as variáveis, assim, formando um roteiro de perguntas aplicadas aos representantes das empresas teutonienses. O levantamento in loco e por conveniência foi realizado pela pesquisadora. A aplicação do pré-teste se deu com quatro professores da instituição de ensino UNIVATES e com quatro empresas.

O estudo exploratório e qualitativo buscou uma amostra do tipo não probabilística, por conveniência. Para atender os objetivos do trabalho foram entrevistados profissionais de empresas que fazem uso do serviço de Medicina Ocupacional, para tanto, entrevistou-se a pessoa responsável pelo departamento de Recursos Humanos e/ou Segurança do Trabalho.

\section{ANÁLISE DOS DADOS E INFORMAÇÕES}

O levantamento de dados deste estudo divide-se em duas partes. Na primeira parte são apresentadas as respostas relativas ao perfil das empresas entrevistadas, onde se analisou o número de funcionários, segmento, ano em que a empresa foi fundada e médico responsável pela Medicina Ocupacional como pode ser visto no Quadro 1 que segue. É importante ressaltar que, para fins de anonimato, os entrevistados desta pesquisa foram identificados pela letra "E" e número conforme entrevista. O mesmo ocorre na denominação 
do médico responsável, onde se optou identificá-lo apenas com uma letra do alfabeto.

Quadro 1 - Perfil das empresas

\begin{tabular}{|c|c|c|c|c|}
\hline Empresa & $\begin{array}{c}\text { Número de } \\
\text { trabalhadores }\end{array}$ & Segmento & $\begin{array}{c}\text { Ano de fundação } \\
\text { da empresa }\end{array}$ & \begin{tabular}{|c|} 
Médico \\
Responsável
\end{tabular} \\
\hline E1 & 1 & Comércio & 2015 & A \\
\hline E2 & 1 & Indústria & 1997 & B \\
\hline E3 & 2 & Comércio & 2014 & B \\
\hline E4 & 4 & Comércio & 2008 & C \\
\hline E5 & 5 & Prestação de serviços & 2000 & B e D \\
\hline E6 & 6 & Comércio & 2002 & B \\
\hline E7 & 6 & Comércio & 1972 & B e D \\
\hline E8 & 7 & Comércio & 1996 & B e D \\
\hline E9 & 10 & Indústria & 2000 & B e D \\
\hline E10 & 10 & Comércio & 2000 & A \\
\hline E11 & 11 & Prestação de serviços & 1999 & B e D \\
\hline E12 & 11 & Comércio & 1953 & C \\
\hline E13 & 12 & Comércio & 1987 & B e D \\
\hline E14 & 13 & Comércio & 2009 & E \\
\hline E15 & 13 & Comércio & 2000 & B e D \\
\hline E16 & 14 & Prestação de serviços & 2009 & C \\
\hline E17 & 17 & Indústria & 1994 & B e D \\
\hline E18 & 27 & Prestação de serviços & 1988 & E \\
\hline E19 & 28 & Comércio & 1995 & E \\
\hline E20 & 28 & Indústria & 2001 & B e D \\
\hline E21 & 45 & Indústria & 2008 & $\mathrm{~F}$ \\
\hline E22 & 50 & Indústria & 2010 & $\mathrm{~F}$ \\
\hline E23 & 65 & Prestação de serviços & 2004 & $\mathrm{~F}$ \\
\hline E24 & 74 & Indústria & 2001 & B e D \\
\hline E25 & 205 & Prestação de serviços & 1956 & C \\
\hline E26 & 215 & Indústria & 2005 & $\begin{array}{l}\text { Preservou o } \\
\text { nome dos dois } \\
\text { profissionais }\end{array}$ \\
\hline E27 & 230 & Indústria & 2014 & $\mathrm{~F}$ \\
\hline E28 & 350 & Indústria & 1997 & $G$ \\
\hline E29 & 417 & Indústria & 1983 & $\mathrm{H}$ \\
\hline E30 & 640 & Indústria & 1981 & I \\
\hline
\end{tabular}

Fonte: Autores, 2016. 
Conforme o quadro anterior, no grupo de 30 entrevistados identificase 11 indústrias (calçados, marcenarias e laticínios), representando $37 \%$ das entrevistadas; 13 comércios (lojas de calçados, roupas, móveis e eletrodomésticos, bazar, material de escritório, alimentação e combustíveis), totalizando $43 \%$ das entrevistadas; e 6 prestadores de serviços (academias, imóveis, alimentação, consertos de eletrodomésticos), representando $20 \%$ das entrevistadas. Entre as empresas entrevistadas, encontram-se empresas dos mais variados tempos de atuação, sendo que a mais antiga foi fundada em 1953, até empresas mais novas, como é o caso de uma fundada em 2015. No entanto, a média de idade é de 20,06 anos.

Quanto ao profissional que realiza o serviço de Medicina Ocupacional, constatou-se que duas das empresas entrevistadas não contratam profissionais de Teutônia, sendo os mesmos da cidade de Lajeado/RS (médicos H e I). Entre as empresas que contratam seu profissional em Teutônia/RS, obteve-se $o$ seguinte resultado: $7 \%$ contratam o médico $\mathrm{A}, 11 \%$ contratam o médico $\mathrm{B}, 37 \%$ contratam os médicos B e D, $15 \%$ contratam o médico C, $15 \%$ contratam com o médico F, 11\% contratam o médico E e 4\% contratam o médico G. Ressalta-se que uma empresa entrevistada apenas afirmou ter dois médicos que prestam serviço, no entanto, preferiu preservar seus nomes e cidade.

O estudo permitiu a percepção de que $47 \%$ das empresas entrevistadas têm o serviço de Medicina Ocupacional contratado por meio de uma empresa de Saúde Ocupacional Privada, denominada neste estudo, para preservar o nome da mesma, como Empresa Alpha, contra 50\% das entrevistadas que buscam o profissional de maneira particular. Ainda, 3\% não disseram de que forma contrata seus profissionais.

A seguir apresentam-se os dados e informações relativos aos fatores importantes e determinantes para decisão e que demonstram a percepção do profissional responsável pela prestação dos serviços de medicina ocupacional.

\section{Bens tangíveis}

Quanto à apresentação do ambiente de trabalho, o mesmo deve ser limpo, organizado, espaçoso, em perfeito estado de conservação, agradável e confortável para o paciente. O E25 enfatizou que "a Vigilância Sanitária de Teutônia já tem uma atuação muito forte no sentido de limpeza e manutenção, então para a empresa, é importante que, além do exigido pela legislação, o local deve ser tranquilo e calmo". Em relação à aparência do material associado, todos consideram importante a boa aparência, pois de acordo com E30, "sem sombra de dúvida o material associado deve ser de boa aparência, tanto o ambiente, quanto o profissional devem transmitir uma boa imagem". Outro ressalta que a aparência transmite profissionalismo, credibilidade e segurança.

Há uma forte tendência quanto à importância de equipamentos modernos, onde, a maioria, ou seja, 26 entrevistados (87\%) salientam que os 
mesmos são importantes, pois trazem mais agilidade, precisão e qualidade na realização do atendimento. O E10 afirmou que "o equipamento moderno traz um melhor resultado, a tecnologia está avançando, então temos que fazer uso dos recursos disponíveis". No entanto, para aqueles que não consideram importante o equipamento moderno ( $13 \%$ dos entrevistados), vale ressaltar a opinião de E8 que afirma que "o importante é o profissionalismo e a competência do que somente ter equipamentos modernos". No mesmo sentido, o E29 afirma que "o importante é ter equipamentos que suprem a necessidade do atendimento, não precisam ser modernos".

A importância da localização do consultório, para a maioria dos entrevistados $(77 \%)$ é, sim, importante ter uma boa localização, que seja um local de fácil acesso, a fim de evitar a perda de tempo com o deslocamento e que, conforme ressalta o E25, "atenda às questões de acessibilidade". Para outros (10\% dos entrevistados), é importante, mas conforme E28, "localização não é tudo, têm outros fatores mais importantes". E por último, 4 entrevistados, que representam $13 \%$, afirmaram que mais importante que a localização, conforme E14, "o profissional deve ser bom no que faz", ou seja, o bom atendimento é mais relevante.

\section{Confiabilidade}

Quanto à segurança e cuidado com os dados disponibilizados pela empresa ao médico, todos afirmaram que o médico trata os mesmos com segurança e cuidado, conforme E25, "a ética médica no atendimento é muito importante". O cumprimento de prazos e agendas previamente combinadas é considerado importante por todos os entrevistados, pois as empresas se organizam de acordo com as datas previamente estipuladas. De acordo com E24, "com certeza, é muito importante para se organizar e evitar problemas futuros com órgãos fiscalizadores ou, até reclamatórias trabalhistas, onde não se consiga comprovar a preocupação com a saúde do trabalhador por falta de exames periódicos".

Quanto à ocorrência de erros ou contratempos no atendimento médico ocupacional, 25 entrevistados (83\%) afirmaram que não ocorrem. Porém, 5 entrevistados afirmaram que, eventualmente, ocorrem contratempos oriundos de atrasos, falta de comunicação entre as partes, mas raramente ocorrem erros.

\section{Conhecimento}

A confiança e a credibilidade são percebidas por $80 \%$ dos entrevistados por meio da experiência, profissionalismo, pela segurança transmitida pelo médico. $\mathrm{O}$ E4 afirmou que considera muito relevante para adquirir a confiança no profissional "a conviç̧ão do mesmo em transmitir informações para a empresa, comprometendo-se com o cliente e com o funcionário, não restando dúvidas entre as partes". O E16 afirmou que "a empresa já comparou com o 
serviço realizado por outros profissionais e os mesmos não demonstraram competência e segurança nas informações e serviço prestado". É importante para alguns, além dos anos de experiência, que o médico faça uma boa anamnese do funcionário. O E25 salienta que a confiança e a credibilidade são vistas "pelos anos de experiência do profissional, levando em consideração a relação médico/cliente, bem como a educação e respeito, atendendo o paciente com a preocupação de olhar nos olhos no mesmo, prestando atenção ao que o paciente fala e examinando-o atentamente".

É de suma importância que as informações prestadas à empresa sejam claras e seguras, para E4 "a clareza e segurança é fundamental para que não fiquem dúvidas entre as partes envolvidas". O E18 complementou que é importante, no entanto, percebe que sua empresa "não recebe um bom feedback quanto à saúde do trabalhador, não sabendo se ocorre ou não algum agravamento na saúde do mesmo" em decorrência dos riscos aos quais o mesmo está exposto. De acordo com três entrevistados (10\%), é importante, tendo em vista que a empresa adquire confiança em relação ao profissional e ainda evita eventuais sansões em fiscalizações. O conhecimento amplo e atualizado do médico na área de atuação é considerado importante por todos os entrevistados e, segundo E30, "é condição mínima para estar atuando na empresa".

Quanto ao preço cobrado pelo serviço, a maioria (90\%) afirmou que o preço está de acordo com o serviço prestado. De acordo com E11 "o mesmo estudou para isso, é o nome dele que está em jogo caso surgir algum problema". No entanto, três entrevistados $(10 \%)$ consideram o preço alto, levando em consideração o fato de ser um atendimento rápido e superficial. Quando relacionado ao tipo de contrato de prestação de serviço, percebe-se que aqueles que consideram ser caro, têm seus serviços contratados pela Empresa Alpha.

\section{Empatia}

A educação e cordialidade no atendimento médico são consideradas de extrema importância por todos os entrevistados, tendo em vista que, segundo E25 "ninguém gosta de ser mal atendido [...] ter educação e cordialidade é tudo em um atendimento, independente da área de atuação, faz o cliente se sentir valorizado". Vários entrevistados afirmaram que a educação é essencial para que a pessoa se sinta bem e fique mais à vontade para expor suas queixas, ou seja, ela gera confiança, segundo E27, "fazendo com que o paciente também vai ser recíproco e ficar mais tranquilo para informar algo em relação a sua saúde". O E16 salientou a importância da educação, "pois acima de qualquer coisa, é importante ter um respeito muito grande pelo paciente". Neste sentido E18 complementou que "o sorriso no rosto é muito importante em qualquer tipo de atendimento, pois é possível transmitir calma e tranquilidade". 
Quanto à atenção individual necessária ao bom atendimento observouse uma pequena divisão nas opiniões, onde 28 entrevistados (93\%) afirmaram que o médico dá a atenção necessária, inclusive, obteve-se o relato de uma entrevistada que trocou de profissional por tal motivo. Enquanto que os outros dois $(7 \%)$, afirmaram que o médico não dá atenção individual necessária, tendo em vista que o atendimento ocorre de maneira rápida, tornando, assim, o atendimento superficial. Mais uma vez, os entrevistados que afirmam que o atendimento ocorre sem a atenção necessária, tem seu profissional contratado via Empresa Alpha.

Percebeu-se uma divisão nas opiniões quanto à dedicação e preocupação do médico na realização do atendimento, onde para E30, "o médico deve levar um tempo mínimo para os atendimentos, fazendo as avaliações necessárias na prevenção de doenças ocupacionais", ou seja, cada caso requer uma dedicação e preocupação de acordo com os riscos aos quais o funcionário está exposto. Para a maioria dos entrevistados $(90 \%)$, o médico preocupa-se e dedica-se ao atendimento. No entanto, destes, $11 \%$ destacaram que o médico poderia aprofundar-se um pouco mais na realização do atendimento. Já, 10\% dos entrevistados, responderam no mesmo sentido que E5, o qual afirmou que "o médico não desprende o tempo necessário para a boa e correta avaliação do paciente/funcionário. $\mathrm{O}$ atendimento é muito superficial, não existe uma preocupação em investigar a saúde do trabalhador". Trata-se, novamente, de empresas que contratam seus profissionais via Empresa Alpha.

\section{Presteza}

Todos os entrevistados afirmaram que o médico demonstra boa vontade em atender. A E26 afirmou que já passou "por situações delicadas com outros profissionais que não demonstravam vontade em atender os funcionários". Portanto, hoje considera muito importante a boa vontade do profissional. Quanto à agilidade para atender ao pedido da empresa, 28 entrevistados afirmaram que ele ocorre de maneira ágil, de acordo com a normalidade e de acordo com a complexidade exigida para o caso. Apenas dois consideraram que o atendimento é muito demorado.

Em relação à disponibilidade do médico em atender a empresa, 28 entrevistados (que representam 93\%) afirmaram que, de acordo com o bom senso dos envolvidos, o profissional tem disponibilidade para lhe atender. O E6 afirmou que, "em casos urgentes, o profissional busca uma maneira de reorganizar sua agenda para atender a empresa". Outros dois entrevistados afirmaram que os agendamentos devem ser realizados com alguns dias de antecedência. O E9 demonstrou-se insatisfeito afirmando que "nem sempre o médico demonstra disponibilidade para a empresa, às vezes é complicado conseguir agendar um horário". 
Quanto à importância da flexibilidade do médico e disposição para atender pedidos especiais e em horários diferenciados, 27 entrevistados $(90 \%)$ afirmaram ser muito importante para a empresa, pois conforme E21 "muitas vezes, o funcionário não consegue sair da empresa em horário comercial" ou então em algum caso de urgência. Salienta-se que a maioria considera importante, mas, mesmo assim, de acordo com o E7, "nem sempre o médico consegue oferecer esta flexibilidade para a empresa". Para os outros três entrevistados (10\%), não é importante esta flexibilidade.

As empresas que têm contratado os serviços da Empresa Alpha (47\%) recebem mensalmente uma carta informando quais os funcionários que devem realizar exames no decorrer do mês. Assim, o controle fica a cargo da Empresa Alpha, no entanto, consideram ser importante que o médico também tenha o mesmo controle para este se programar em relação à demanda. Para E26, esta preocupação deve se dar "a fim de evitar reclamatórias trabalhistas onde a empresa não consiga se defender por falta de prova de estar preocupada com a saúde ocupacional do funcionário por meio de exames rotineiros". Já o E30 destacou ainda a importância de o médico acompanhar "o controle de riscos abordados no PCMSO e implantação e acompanhamento de programas de saúde ocupacional". Já $23 \%$ afirmam que preferem fazer o controle na empresa, não vendo necessidade de o médico ter esse controle. As demais empresas $(30 \%)$ consideram importante que o médico faça este controle, tendo em vista, conhecer melhor os prazos e para evitar a sobrecarga de responsabilidade da empresa.

O presente estudo visou analisar a percepção da qualidade do serviço prestado pelos médicos de Medicina Ocupacional às empresas da cidade de Teutônia/RS. Tendo por base os dados coletados na pesquisa, foram analisadas cada uma das dimensões conforme segue.

De acordo com a dimensão Bens tangíveis, percebe-se que as empresas entrevistadas consideram importante a higienização e a manutenção corretas do estabelecimento, a utilização de recursos capazes de suprir as necessidades de atendimento e uma boa aparência dos mesmos. Salientam ainda, a importância da boa localização do consultório. Tal dimensão, de modo geral, é bem percebida pelos entrevistados, não constatando divergências entre literatura e realidade, conforme Fitzsimmons e Fitzsimmons (2014), esta dimensão deve levar em consideração a preocupação dos profissionais em atentar aos detalhes que podem ser cruciais em uma avaliação positiva ou não do estabelecimento.

$\mathrm{Na}$ dimensão Confiabilidade, os entrevistados, de modo geral, percebem positivamente a qualidade do serviço, salientando a importância da segurança e do cuidado com os dados disponibilizados pelas empresas e o cumprimento dos prazos e agendas estabelecidos. No entanto, alguns destacam que erros e contratempos devem, ainda, ser minimizados. Destarte, percebe-se um desacordo com a literatura, pois, conforme Garvin (1992) e Fitzsimmons e Fitzsimmons (2014), é importante atentar a todas as etapas e níveis do serviço 
para que o mesmo possa ser realizado com confiança e exatidão. Os erros e contratempos, de acordo com os entrevistados, podem ser determinantes para a confiança ou não no serviço prestado. Pois, a confiança e a credibilidade, juntamente com o profissionalismo são as cobranças por um serviço qualificado e comprometido com as necessidades das empresas.

A satisfação do cliente, segundo Johnston e Clark (2009), é afetada por muitos aspectos da organização de serviço, incluindo sua imagem de marca. Assim, conforme ressaltado pelos entrevistados é preciso atentar aos detalhes em torno da imagem do serviço, tendo em vista que estes são importantes para a obtenção da confiança. Neste sentido, Sirdeshmukh, Singh e Sabol (apud VARGAS; SCHALENBERGER; HÖRBE, 2014) afirmam que a confiança deve ser algo construído entre as partes. Portanto, deve-se considerar as necessidades básicas do cliente elencadas por Schneider e Bowen (apud MILAN, 2002), sendo elas, segurança, justiça e autoestima.

$\mathrm{Na}$ dimensão Conhecimento os entrevistados consideram de suma importância a necessidade de conhecimento amplo e atualizado com informações prestadas de maneira clara e segura, demonstrando credibilidade em suas afirmações. Tal dimensão, de modo geral, é bem percebida, tendo obtido respostas positivas em relação à maioria dos quesitos elencados, não sendo, portanto, constatadas divergências significativas entre literatura e realidade. Constatou-se, no entanto, que um pequeno percentual alega que o valor cobrado pelo serviço não está de acordo com o serviço prestado. Neste sentido, Fitzsimmons e Fitzsimmons (2014) ressaltam a importância de uma comunicação efetiva entre as partes com o intuito de demonstrar que a organização está interessada em prestar o melhor serviço para o cliente. Esta insatisfação percebida por determinadas empresas, quando relacionada com a forma de contratação do profissional, evidencia que são casos pontuais relacionados a profissionais que realizam o atendimento à empresa por meio da Empresa Alpha.

A dimensão Empatia teve uma boa percepção por parte dos entrevistados. Os mesmos consideram de grande valia a cordialidade e a educação, aliadas a um atendimento individual com dedicação e preocupação necessária para realizar um bom atendimento. A educação e cordialidade são as cobranças pelo bom atendimento, valorizando as partes envolvidas, onde, de acordo com as entrevistas é fator que constrói a confiança no profissional. Da mesma forma que na dimensão analisada anteriormente, percebe-se um pequeno grau de insatisfação por determinadas empresas que contratam seus profissionais por meio da Empresa Alpha. Neste sentido, Mezomo (1995) salienta que os médicos devem atentar ao poder dos clientes e que, portanto, precisam entender que o bom relacionamento com todos, é fator de bem-estar e de realização profissional. Assim, de acordo com o autor, justificada a exigência feita por parte dos entrevistados quanto à educação, cordialidade, dedicação e preocupação necessárias para realizar um bom atendimento. 
Os resultados das perguntas que avaliam a dimensão Presteza são os que mais preocupam no que diz respeito à análise geral das dimensões. Isto porque diversas queixas foram evidenciadas pelos responsáveis das empresas entrevistadas, tais como, atendimento superficial, demora no agendamento, ou seja, pouca disponibilidade e falta de flexibilidade do profissional para atender a empresa. Entretanto, tal resultado não deve ser generalizado, tendo em vista, mais uma vez, que as queixas estão relacionadas às empresas que têm o serviço prestado pela Empresa Alpha. Já em relação aos demais entrevistados, os mesmos têm uma boa percepção da prestação dos serviços.

Conforme as respostas dos entrevistados, entende-se que as dimensões da qualidade de serviço que mais influenciam e que, portanto, são construtoras da percepção dos mesmos, são educação e cordialidade, profissionalismo e; confiança e credibilidade no serviço. De acordo com Mezomo (1995), o que mais se destaca é a maneira como os médicos se relacionam com os seus clientes e não tanto pelo seu conhecimento ou a tecnologia que usam. Complementa ainda, dizendo que:

Os que não entendem isso estão pondo em risco a própria vida da instituição, porque os clientes de hoje estão mais conscientes de seus direitos e de sua dignidade e cobram mais pelo que pagam. Os clientes nem sempre têm condições para avaliar o conhecimento e a técnica, mas sabem avaliar muito bem o nível da atenção que lhes é dada. Nisso eles são tão "doutores" quanto os que o são por diploma (MEZOMO, 1995, p. 95).

Segundo Slack (apud BAPTISTA; LEONARDT, 2011), qualidade deve ser vista como a conformidade com as expectativas dos consumidores, porém, basear a definição de qualidade em expectativas pode ser um problema, pois elas variam entre os usuários, com isso, as percepções também variam. Nos serviços essa variação acontece pelo fato de serem intangíveis, e isso leva os usuários a terem percepções diferentes em diversos momentos.

Assim, entende-se a preocupação demonstrada pelos entrevistados em afirmar a importância de confiança e credibilidade, juntamente com o profissionalismo nos serviços prestados. De modo geral, a percepção avaliada no presente estudo mostra que a maioria das empresas está satisfeita e, destarte, percebem de maneira positiva o serviço que está sendo realizado pelos médicos de Medicina Ocupacional na cidade de Teutônia/RS.

\section{CONSIDERAÇÕES FINAIS}

O presente estudo buscou analisar a percepção da qualidade do serviço prestado pelos médicos de Medicina Ocupacional às empresas da cidade de Teutônia/RS, que busca contribuir para a elucidação de problemas 
relacionados às escolhas e contratações de médicos que prestam serviços na Medicina Ocupacional para as empresas.

Após a análise dos resultados, interligados com os objetivos que nortearam o desenvolvimento do estudo, é relevante apresentar as considerações finais que podem influenciar no serviço prestado pelos médicos, buscando o aumento da qualidade do mesmo. O primeiro objetivo específico visava descrever o perfil das empresas. Já o segundo e o terceiro objetivos buscaram entender, por meio das dimensões de qualidade, o que as empresas esperam no atendimento e; avaliaram a percepção dos clientes quanto à qualidade dos serviços prestados, conforme pôde ser visto na apresentação e análise dos dados.

A pesquisa permitiu constatar que as empresas percebem de forma positiva a qualidade dos serviços. As queixas são poucas e, portanto, os médicos estão perto de atingir as expectativas de seus clientes. Os resultados demonstraram que o objetivo do estudo foi atingido. Em geral, o método de pesquisa utilizado se mostrou apropriado para medir a qualidade dos serviços prestados. Além disso, pode ser considerado um instrumento de gestão e tomada de decisão, pois evidenciou os pontos fracos e fortes dos serviços, bem como, mostrou ser um meio de contribuir para o sucesso dos consultórios médicos.

Constatou-se que educação e cordialidade, profissionalismo e confiança e credibilidade são fatores importantes para a escolha na contratação do serviço. Destarte, são por meio destas características que os representantes das empresas percebem a qualidade na prestação do serviço. A partir da percepção dos entrevistados, identificou-se oportunidades de melhorias, o que pode ser desdobrado em algumas ações. Assim, sugere-se como ponto de partida, a constante manutenção dos pontos fortes, com a consequente busca de outros que vêm a contribuir positivamente para a boa qualidade do serviço.

Considera-se salutar que seja feita uma análise do serviço que o profissional oferece ao seu cliente, elencando, dessa forma, os pontos positivos. Na sequência, sugere-se que o profissional identifique junto ao seu cliente um canal de comunicação, possibilitando identificar o que o cliente espera. No entanto, deve-se levar em consideração que o cliente procura inovações e que pode mudar de direção de acordo com suas necessidades. Neste sentido, entende-se que o processo de avaliação deve ser constante, a fim de captar as nuances das necessidades de seus clientes, visando superar as suas expectativas.

As limitações do presente estudo foram, em diversos momentos, as respostas dadas de maneira incompleta às perguntas, retendo informações importantes, dificuldade de expressão e comunicação dos entrevistados e disposição dos mesmos em dar as informações necessárias. A presente pesquisa não atingiu todas as empresas localizadas em Teutônia/RS. Sugere-se que o estudo tenha uma continuidade, assim, estruturando uma forma de entrevistar um maior número de empresas, consequentemente, demandando mais tempo 
para a realização das entrevistas, obtendo-se um maior volume de informações a serem analisadas.

\section{REFERÊNCIAS}

ALBRECHT, Karl; BRADFORD, Lawrence J. Serviços com qualidade: a vantagem competitiva. São Paulo: Makron Books, 1992.

ARGES JUNIOR, Humberto Paulo. Identificação do conhecimento e aplicação dos conceitos de marketing nas clínicas médicas de Cascavel em relação aos serviços prestados. Monografia (Graduação). Curso de Administração da UNIOESTE, Cascavel, PR, 2000. Disponível em: <http:/ / www.marketingemsaude. com.br/home/ download/monografia-humbert_junior.pdf >. Acesso em 31 ago. 2015.

BAPTISTA, Michele Marques; LEONARDT, Michele Poleto Lesina. A qualidade dos serviços prestados e a satisfação dos usuários em uma Biblioteca Universitária. Bibl. Univ., Belo Horizonte, v.1, n.1, p. 50-59, jan./jun. 2011. Disponível em: <https:/ / www. bu.ufmg.br/rbu/index.php/localhost/article/viewFile/9/ 14>. Acesso em 02 mar. 2016.

BELLUSCI, Silvia Meirelles. Doenças profissionais ou do trabalho. 11. ed. São Paulo: SENAC, 2010.

BORBA, Valdir Ribeiro; MENDES, Aderrone Vieira; SILVEIRA, Ana Paula Cordeiro de Menezes. Marketing de relacionamento para organização de saúde: fidelização de clientes e gestão de parcerias. São Paulo: Atlas, 2004.

CORRÊA, Henrique Luiz; CAON, Mauro. Gestão de serviços: lucratividade por meio de operações e de satisfação dos clientes. 1. ed. 7. reimpr. São Paulo: Atlas, 2009.

CROSBY, Philip B. Qualidade é investimento. 3. ed. Rio de Janeiro: José Olympio, 1988.

DIAMANTE, Cristina. Modelo de gestão para organizações prestadoras de serviços de saúde. Dissertação (Mestrado). Pós-Graduação em Engenharia de Produção Universidade Federal de Santa Catarina, Florianópolis, SC, 2003. Disponível em: $<$ https: / / repositorio.ufsc.br/xmlui/bitstream/handle/123456789/85877/ 225960. pdf? sequence=1\&isAllowed $=y>$. Acesso em 20 mar. 2016.

ELEUTÉRIO, Sueli Aparecida Varani; SOUZA, Maria Carolina A. F. de. Qualidade na prestação de serviços: uma avaliação com clientes internos. Caderno de Pesquisas em Administração, São Paulo, v.09, nº 3, Julho/Setembro 2002. Disponível em: <http:/ / www.regeusp.com.br/arquivos/v9n3art5.pdf >. Acesso em: 09 out. 2015.

FECOMÉRCIO- RS. Três em cada quatro trabalhadores está no setor de serviços, segundo Sescon. Disponível em: <http:/ / fecomercio-rs.org.br/agencia-noticiasdetalhe.php?noticia =25327>. Acesso em 11 ago. 2015 . 
FITZSIMMONS, James A.; FITZSIMMONS, Mona J. Administração de serviços: operações, estratégia e tecnologia da informação. 7. ed. Porto Alegre: AMGH, 2014.

FORTES, Paulo Antonio de Carvalho. Ética e saúde: questões éticas, deontológicas e legais, tomada de decisão, autonomia e direitos do paciente, estudo de casos. São Paulo: EPU, 1998.

GARVIN, David A. Gerenciando a qualidade: a visão estratégica e competitiva. Rio de Janeiro: Qualitymark, 1992.

GIANESI, Irineu G. N.; CORRÊA, Henrique Luiz. Administração estratégica de serviços: operações para a satisfação do cliente. São Paulo: Atlas, 2009.

GONÇALVES, Edinéia et al. Gestão da Qualidade no Atendimento ao Cliente: Aplicação do Modelo SERVQUAL para mensuração da Qualidade dos Serviços Prestados pela Fisiomed. Revista Eletrônica Gestão e Negócios - Volume $1-\mathrm{n}^{\mathrm{o}}$ 1 - 2010. Disponível em: < http: / / www.facsaoroque.br/novo/publicacoes/pdfs / editorial_adm.pdf>. Acesso em 21 set. 2015.

GRÖNROOS, Christian. Marketing: gerenciamento e serviços. 3. ed. Rio de Janeiro: Elsevier, 2009.

HENRIQUE, Ademir et al. Qualidade na prestação de serviço como diferencial competitivo: um estudo de caso em um escritório de contabilidade no município de Três Lagoas/MS. Faculdades Integradas de Três Lagoas - AEMS, MS, 2013. Disponível em: <http://www.aems.edu.br/conexao/edicaoanterior/Sumario/2013/ downloads/2013/3/32.pdf >. Acesso em: 28 ago. 2015.

JOHNSTON, Robert; CLARK, Graham. Administração de operações de serviço. São Paulo: Atlas, 2009.

LAS CASAS, Alexandre Luzzi. Qualidade total em serviços: conceitos, exercícios, casos práticos. 3. ed. São Paulo: Atlas, 1999.

LOVELOCK, Christopher; WIRTZ, Jochen; HEMZO, Miguel Angelo. Marketing de serviços: pessoas, tecnologia e estratégia. 7. ed. São Paulo: Pearson Prentice Hall, 2011.

MARANO, Vicente Pedro. Medicina do trabalho: controles médicos: provas funcionais. 4. ed. rev. e ampl. São Paulo: LTr, 2001.

MEZOMO, João Catarin. Gestão da qualidade na saúde: princípios básicos. São Paulo: J. C. Mezomo, 1995.

MILAN, Gabriel Sperandio. A estratégia de retenção de clientes e o estabelecimento de relacionamentos como vantagem competitiva: um plano de ações aplicado a uma empresa de medicina de grupo. Dissertação (Mestrado). Curso de Mestrado Profissionalizante em Engenharia apresentado ao Programa de Pós-Graduação em Engenharia de Produção da Universidade Federal do Rio Grande do Sul, 
Porto Alegre, RS: 2002. Disponível em: <https:/ /www.lume.ufrgs.br/ bitstream/ handle/10183/3243/000334661.pdf?sequence=1>. Acesso em: 20 mar. 2016.

MINISTÉRIO DO TRABALHO E EMPREGO. NR 7 - Programa de controle médico de saúde ocupacional. Disponível em: <http://portal.mte.gov.br/data/files / FF8080814295F16D0142E2E773847819/NR-07\%20(atualizada\%202013).pdf>. Acesso em 05 out. 2015.

MOREIRA, Daniel Augusto. Introdução à administração da produção e operações. São Paulo: Pioneira, 1998.

PALADINI, Edson Pacheco. Gestão da qualidade: teoria e prática. 2. ed. São Paulo: Atlas, 2009.

PEREIRA, Adriani; BERTOLINI, Geysler R. F.; BRANDALISE, Loreni T. Qualidade em Serviços: Perfil Real versus Perfil Ideal. Universidade Estadual do Oeste do Paraná, Cascavel, PR, 2003?. Disponível em: <http:/ / www.unioeste.br/campi/ cascavel/ccsa/IISeminario/trabalhos/Qualidade\%20em\%20servi\%C3\%A7os.pdf $>$. Acesso em 20 mar. 2016.

RIBEIRO, Olívio Mendes. Qualidade no atendimento ao cliente como estratégia competitiva. Dissertação (Mestrado). Instituto Superior de Ciências do Trabalho e da Empresa, Portugal, outubro de 2007. Disponível em: <http:/ / www.portaldoconhecimento. gov.cv/bitstream/10961/142/1/ Disserta $\%$ C3\%A7\%C3\%A3o\%20do\%20Mestrado\%20de $\% 2001 \% C 3 \%$ ADvio $\% 20$ Mendes $\% 20$ Ribeiro $\% 20-20$ Cabo $\% 20$ Verde $\% 20 \% 20$ edi $\%$ C3\%A7\%C3\% A3o\%20 20042005.pdf >. Acesso em 20 set. 2015.

SELLES, Alice; MINADEO, Roberto. Marketing para serviços de saúde: um manual de talento e bom senso. Rio de Janeiro: Cultura Médica, 2006.

TÉBOUL, James. A era dos serviços: uma abordagem de gerenciamento. Rio de Janeiro: Qualitymark, 1999.

VARGAS, Katiuscia Schiemer; SCHALENBERGER, Ingrid Monike Severo; HÖRBE, Tatiane de Andrade Neves. Avaliação da qualidade do serviço na representação médica: aplicação da metodologia ServQual. Revista Brasileira de Gestão e Inovação - Brazilian Journal of Management E Innovation v.2, n.1, Setembro/Dezembro, 2014. Disponível em: <http:/ / www.ucs.br/etc/ revistas/index. php/RBGI/article/ viewFile/2999/1745>. Acesso em 06 mar. 2016.

VIEIRA, Sebastião Ivone. (Coord). Medicina Básica do trabalho. Curitiba, PR: Genesis, 1995. 